\title{
Radio-wave Therapy of Inferior Turbinates for Treatment of Intractable Vasomotor Rhinitis - a Clinical Study of the Subjective Long-term Outcome
}

\author{
Ellen A. A. Jaatun ${ }^{1,2, *}$, Claude Laurent ${ }^{3}$ \\ ${ }^{1}$ Department of Otorhinolaryngology, Head and Neck Surgery, St Olav University Hospital, Trondheim, Norway \\ ${ }^{2}$ Department of Cancer Research and Molecular Medicine, Faculty of Medicine, NTNU, Trondheim, Norway \\ ${ }^{3}$ Division of Otorhinolaryngology, Department of Clinical Science, Umeå University, Umeå, Sweden
}

\begin{abstract}
Objective: To evaluate the subjective outcome after treatment with bi-polar radio-wave frequency therapy of the inferior turbinates in patients with vasomotor rhinitis unresponsive to nasal steroid treatment.Material and Methods: Details of 151 patients with vasomotor rhinitis were collected from an electronic patient-record system. The main indication for turbinectomy with radio-wave frequency therapy was nasal congestion. Using a questionnaire with a follow-up time between 9 and 33 months, radio-wave therapy demonstrated good subjective results with respect to nasal congestion and patient relief. No serious side effects were reported.Conclusion: Radio-wave frequency therapy is a low cost procedure suitable for out-patient clinics; the procedure is easy to perform and has a good long term effect on nasal congestion in patients with intractable vasomotor rhinitis.
\end{abstract}

Keywords Cautery, Man, Nasal Obstruction, Radio-Wave Therapy, Rhinorrhoea, Surgery, Turbinates, Vasomotor Rhinitis

\section{Introduction}

Vasomotor rhinitis is a common diagnosis in an ENT practice. It is characterised by nasal congestion, runny nose and sneezing. The patient's symptoms are much the same as in allergic rhinitis, in particular nasal blockage and secretion, but allergy tests are negative. As in allergic rhinitis the patients have nasal hyperreactivity when exposed to stimuli such as perfume, spicy food, red wine, ink (from printed newspapers), dust, and temperature changes. The standard treatment of vasomotor rhinitis is a local nasal steroid administered as powder, drops or spray. For the majority of patients this will give good relief and be a sufficient therapy. In cases with a severely running nose, local treatment with Ipratropiumbromide has also been effective[1].

In some cases with more intractable disease, the pharmaceutical treatment is not sufficient and surgical methods must be considered. Throughout the years many different surgical methods have been offered to treat intractable vasomotor rhinitis, such as submucosal diathermy[2], laser- turbinectomy[3], cryotherapy[4] and surgical turbinectomy in different forms $[4,5]$. These therapies offer relief to various

* Corresponding author:

ellen@atilf.no (Ellen A. A. Jaatun)

Published online at http://journal.sapub.org/cmd

Copyright (C) 2012 Scientific \& Academic Publishing. All Rights Reserved extents, but none give a 100\% relief from all symptoms. In a long term study there was no significant difference in success rate between different methods of turbinate reduction[4]. As the majority of the patients have hypertrophic inferior turbinates, the different surgical procedures aim to shrink this area. Common problems and side-effects with many of the above mentioned methods have been bleeding, crust formation and synechia. The procedures have had a high cost due to the fact that the patients have mainly been in-patients and the complication rate has been high[4]. Some of the therapy forms also have been expensive due to the required instruments.

During the last few years a few articles have been published about other methods of treatment in out-patient clinics at a lower cost and with fewer complications[2, 3, 6, 7]. These methods also focus on the reduction of the inferior turbinates with a variety of therapies.

Radio-wave frequency therapy for medical purposes was introduced in the end of the 1990-ies[8]. The bi-polar radio-wave therapy is a non-traumatic way to coagulate and cut soft tissue; the generated heat leads to necrosis of the tissue between the electrodes. Radio-wave therapy is especially attractive when per-operative bleeding is a problem. So far, there are only a few published studies about turbinate treatment with radio-wave therapy[8, 9, 10]. Although numbers of patients treated has been limited, the results have been satisfactory[8]. 
This study of a large group of vasomotor rhinitis patients aims to evaluate the subjective outcome after treatment with bi-polar radio-wave frequency therapy of the inferior turbinates after failure with previous medical therapy. In order to facilitate the treatment procedure and bring down the treatment costs this study was mainly performed in out-patient clinics.

\section{Materials and Methods}

\subsection{Patients}

The patient material (consisting of 191 patients with established vasomotor rhinitis) was collected from an electronic patient-record system at the ENT Department at the Nordland Central Hospital in Bodø, Norway. The search was made using the procedure code DHB 40 for conchotmy/turbinectomy according to the classification of surgical procedures, NOMESCO 1996[11]. All patients between January 2000 and April 2003 registered with this code were printed out with name, date of birth, time for the procedure, and information whether they were in- or out-patients. All patients who had undergone septal surgery concurrently with or after the radio-wave therapy were excluded, as were the ones who were diagnosed with acute or chronic sinusitis (at the time of operation or later). All patients had been prescribed a local nasal steroid for at least 3 months before the operation. The steroid treatment was then evaluated and, if determined to be unsuccessful, the patients were subsequently scheduled for an out-patient treatment procedure with radio-wave therapy of the inferior turbinates. Upon examination of each patient's record it was determined that the indication for every radio frequency turbinectomy was nasal congestion and, thus, every patient should have reported nasal congestion before the procedure. In a few cases $(n=29)$ the treatment was given in conjunction with uvulo-palato-pharyngoplasty (UPPP) with patients admitted as in-patients. Replies of a questionnaire from 151 patients were included in the survey (107 males and 44 females), varying in age from 21 to 85 years (men 21 to 85 years; women 21 to 74 years), mean age 47 years.

The out-patients' treatment was given under local anaesthesia. All patients returned home immediately after treatment. The follow-up time was between 9 and 33 months.

\subsection{Radio-wave frequency therapy.}

Bi-polar radio-wave frequency treatment was given bilaterally in the inferior turbinates using an Ellman Surgitron IEC radio-wave therapy machine (Ellman International Inc, Hawlett, New York, USA). The frequency used was 1.7 $\mathrm{MHz}$ with a power setting of 25, corresponding to an output of $18 \mathrm{~W}$ (the maximum output is $120 \mathrm{~W}$ ).

The patients were lying in the supine position with the head slightly elevated. Local anaesthetic spray (Xylocain, $10 \mathrm{mg} /$ dose) was applied 2-3 times in each nostril. After 5 minutes, an injection of $1,8 \mathrm{ml}$ of Xylocain with adrenaline
(Lidocain $20 \mathrm{mg} / \mathrm{ml}+$ adrenaline $0.0125 \mathrm{mg} / \mathrm{ml}$ ) was made in each inferior turbinate.

The bi-polar electrode was then inserted submucosally into the inferior turbinate along its anterior free border, longitudinally about $2 / 3$ of the turbinate length. A burst of current, approximately of two seconds duration, was used until visual blanching occurred. The electrode was then withdrawn past the blanched area and the procedure was repeated until the whole area was treated. After the procedure the inferior turbinate was clearly shrivelled. After finishing the treatment of both sides of the nose, the nostrils were left open without any packing, but when visible crusts or burns were noted on the surface of the turbinates, an ointment with antibiotics (Fucidin 2\% or Terracortril cum Polymyxin-B) was locally applied. The treatments were performed by ENT surgeons with varying degrees of surgical experience. However, the same technique was used by all of them.

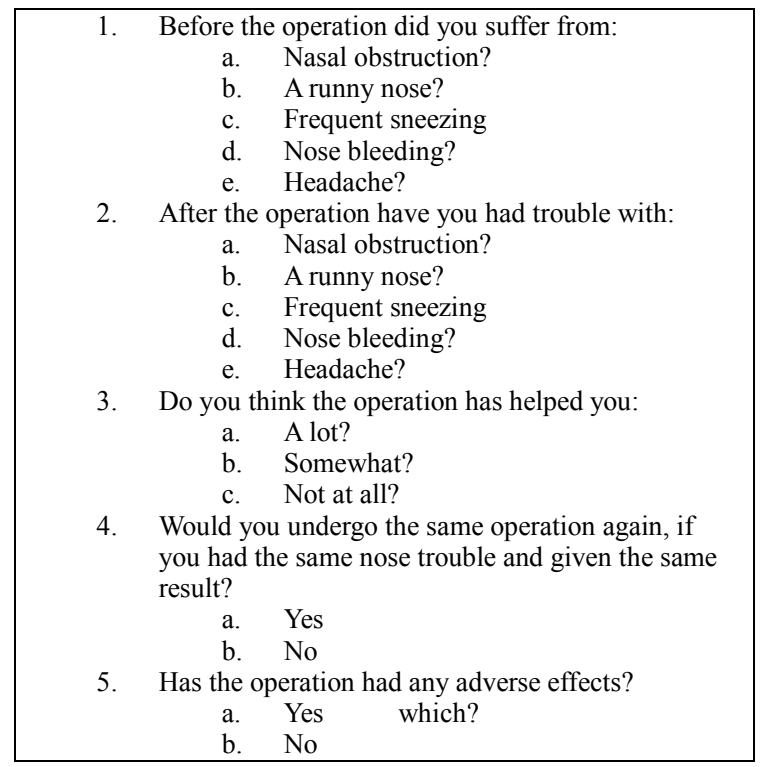

Figure 1. The questionnaire sent out to patients.

\subsection{Questionnaire follow-up.}

191 patients received a questionnaire to elicit the patient's opinion regarding specific items (Figure 1). The set-up of questions was about nasal congestion pre- and post-operatively, and whether they had suffered from runny nose, sneezing, nose bleeds or headache before or after the procedure. They were also asked to grade the effect of the treatment from helping a lot, somewhat or not at all. There was also a question - if they would undergo the same procedure again having the same nose troubles and given the same long-term result? Finally, they were asked about side-effects or complications.

Due to the introduction of a new computerized patient record system at the hospital in January 2002, the patient material was divided into two groups with different observation times. The first group of 59 patients consisted of those who had the radio-wave treatment done between June 2000 and January 1st 2002. The observation time was minimum 
21 months and maximum 33 months. The second group of 92 patients had undergone surgery at two different time periods, but both sub-groups had a minimum observation time of 9 months. The first sub-group of 53 patients were treated between January 2002 and January 2003 and the questionnaires were returned before September 2003. The second sub-group of 39 patients had the treatment done between January 2003 and April 2003 and they returned the questionnaire before December 2003.

\section{Results}

151 patients out of $191(78 \%)$ responded (some after a written reminder) and were included in the study. Looking at the results in the respective tables, one should be aware of the fact that some patients did not give an answer to every question and, accordingly, no columns add up to $100 \%$.

Table 1 shows the result regarding the subjective outcome after radio-wave frequency treatment in the whole material. Although $59 \%$ of the patients reported post-operative nasal congestion, as many as $78 \%$ answered that they would undergo the same procedure again having the same nose troubles and given the same long-term result. Only $6 \%$ of the patients reported adverse effects, all of which were minor in category. Most of the patients reporting adverse effects had more than 1 symptom. The reported complaints were 5 sneezing, 8 postoperative epistaxis, 3 crusting, 8 runny nose and 1 sinusitis - none of which needed any medical attention.

Table 2 shows the patient material divided into two groups with a 21 months and a 9 months observation time, respectively. As many as $61 \%$ and $58 \%$ of the patients in the two groups, respectively, reported nasal congestion after the procedure. Nevertheless, it had obviously helped $80 \%$ of them, and $71-83 \%$ of the responding patients reported that they would undergo the same operation again if they could expect a similar result.

Table 3 shows the result for men and women. One obvious difference between the sexes were that all women were nasally blocked pre-operatively and that the positive effect of the treatment on the nasal congestion in females increased with longer observation time, whereas the men apparently became more nasally blocked with increasing time after the procedure. Among the men, about $20 \%$ responded that the procedure had not helped, whereas about $80 \%$ found some or a good relief after the treatment. In the women between 13 and $15 \%$ replied that the procedure had not helped. There were also more adverse effects reported among men as compared with women $(n=7$ versus $n=2)$. However, no complications needed any special medical attention.

The pre- and postoperative occurrence of other symptoms associated with vasomotor rhinitis is summarized in Table 4. There was no major change in any of these symptoms after treatment. However, it was noted that only $14 \%$ had headache post-operatively as compared with $23 \%$ before surgery.

Table 1. The subjective outcome after radio-wave frequency treatment in the whole material $(n=151)$.

\begin{tabular}{|c|c|c|c|c|c|c|c|c|c|}
\hline & \multicolumn{2}{|c|}{$\begin{array}{c}\text { Nasal congestion pre- and } \\
\text { post-operative }\end{array}$} & \multicolumn{3}{|c|}{$\begin{array}{c}\text { Helped a lot, somewhat or } \\
\text { not at all }\end{array}$} & $\begin{array}{c}\text { Would do it again } \\
\text { with same result }\end{array}$ & \multicolumn{3}{c|}{ Adverse effect } \\
\hline & pre & post & a lot & some & not & yes & no & Yes & no \\
\hline $\mathrm{N}(=151)$ & 145 & 89 & 59 & 63 & 29 & 118 & 30 & 9 & 136 \\
\hline$\%$ & 96 & 59 & 39 & 42 & 19 & 78 & 20 & 6 & 90 \\
\hline
\end{tabular}

Table 2. The subjective outcome after radio-wave frequency treatment after 9 months and 21 months.

\begin{tabular}{|c|c|c|c|c|c|c|c|c|c|}
\hline \multirow[t]{2}{*}{ Observation time } & \multicolumn{2}{|c|}{$\begin{array}{l}\text { Nasal congestion pre- } \\
\text { and post-operative }\end{array}$} & \multicolumn{3}{|c|}{$\begin{array}{c}\text { Helped a lot, somewhat or not at } \\
\text { all }\end{array}$} & \multicolumn{2}{|c|}{$\begin{array}{l}\text { Would do it again with } \\
\text { same result }\end{array}$} & \multicolumn{2}{|c|}{ Adverse effect } \\
\hline & pre & post & a lot & some & not & yes & no & yes & no \\
\hline $\begin{array}{l}21 \text { months } \\
\text { (59 patients) }\end{array}$ & $\begin{array}{c}58 \\
(98 \%)\end{array}$ & $\begin{array}{c}36 \\
(61 \%)\end{array}$ & $\begin{array}{c}26 \\
(44 \%)\end{array}$ & $\begin{array}{c}22 \\
(37 \%)\end{array}$ & $\begin{array}{c}12 \\
(20 \%)\end{array}$ & $\begin{array}{c}42 \\
(71 \%)\end{array}$ & $\begin{array}{c}15 \\
(25 \%)\end{array}$ & $\begin{array}{c}2 \\
(3 \%)\end{array}$ & $\begin{array}{c}53 \\
(90 \%)\end{array}$ \\
\hline $\begin{array}{l}9 \text { months } \\
\text { (92 patients) }\end{array}$ & $\begin{array}{c}87 \\
(95 \%)\end{array}$ & $\begin{array}{c}53 \\
(58 \%)\end{array}$ & $\begin{array}{c}33 \\
(35 \%)\end{array}$ & $\begin{array}{c}41 \\
(45 \%)\end{array}$ & $\begin{array}{c}18 \\
(20 \%)\end{array}$ & $\begin{array}{c}76 \\
(83 \%)\end{array}$ & $\begin{array}{c}15 \\
(16 \%)\end{array}$ & $\begin{array}{c}7 \\
(8 \%)\end{array}$ & $\begin{array}{c}83 \\
(90 \%)\end{array}$ \\
\hline
\end{tabular}

Table 3. The subjective outcome after radio-wave frequency treatment in females and males.

\begin{tabular}{|c|c|c|c|c|c|c|c|c|c|c|}
\hline & \multirow[t]{2}{*}{ Observation time } & \multicolumn{2}{|c|}{$\begin{array}{l}\text { Nasal congestion pre- } \\
\text { and post-operative }\end{array}$} & \multicolumn{3}{|c|}{$\begin{array}{c}\text { Helped a lot, somewhat or not at } \\
\text { all }\end{array}$} & \multicolumn{2}{|c|}{$\begin{array}{l}\text { Would do it again } \\
\text { with same result }\end{array}$} & \multicolumn{2}{|c|}{ Adverse effect } \\
\hline & & pre & post & a lot & some & not & yes & no & yes & no \\
\hline \multirow{2}{*}{ 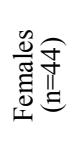 } & $\begin{array}{l}21 \text { months } \\
\text { (20 patients) }\end{array}$ & $\begin{array}{c}20 \\
(100 \%)\end{array}$ & $\begin{array}{c}10 \\
(50 \%)\end{array}$ & $\begin{array}{c}11 \\
(55 \%)\end{array}$ & $\begin{array}{c}6 \\
(30 \%)\end{array}$ & $\begin{array}{c}3 \\
(15 \%)\end{array}$ & $15(75 \%)$ & $\begin{array}{c}5 \\
(25 \%)\end{array}$ & $\begin{array}{c}0 \\
(0 \%)\end{array}$ & $\begin{array}{c}20 \\
(100 \%)\end{array}$ \\
\hline & $\begin{array}{l}9 \text { months } \\
\text { (24 patients) }\end{array}$ & $\begin{array}{c}24 \\
(100 \%)\end{array}$ & $\begin{array}{c}19 \\
(79 \%)\end{array}$ & $\begin{array}{c}10 \\
(41 \%)\end{array}$ & $\begin{array}{c}11 \\
(46 \%)\end{array}$ & $\begin{array}{c}3 \\
(13 \%)\end{array}$ & $\begin{array}{c}19 \\
(79 \%)\end{array}$ & $\begin{array}{c}3 \\
(13 \%)\end{array}$ & $\begin{array}{c}2 \\
(8 \%)\end{array}$ & $\begin{array}{c}11 \\
(46 \%)\end{array}$ \\
\hline \multirow{2}{*}{$\frac{\sqrt[0]{\tilde{\sigma}}}{\sum^{\pi} \frac{\pi}{\Xi}}$} & $\begin{array}{l}21 \text { months } \\
\text { (39 patients) }\end{array}$ & $\begin{array}{c}38 \\
(97 \%)\end{array}$ & $\begin{array}{c}26 \\
(67 \%)\end{array}$ & $\begin{array}{c}15 \\
(38 \%)\end{array}$ & $\begin{array}{c}17 \\
(44 \%)\end{array}$ & $\begin{array}{c}8 \\
(20 \%)\end{array}$ & $\begin{array}{c}27 \\
(69 \%)\end{array}$ & $\begin{array}{c}10 \\
(25 \%)\end{array}$ & $\begin{array}{c}2 \\
(5 \%)\end{array}$ & $\begin{array}{c}33 \\
(84 \%)\end{array}$ \\
\hline & $\begin{array}{l}9 \text { months } \\
\text { (68 patients) }\end{array}$ & $\begin{array}{c}63 \\
(92 \%)\end{array}$ & $\begin{array}{c}34 \\
(50 \%)\end{array}$ & $\begin{array}{c}23 \\
(34 \%)\end{array}$ & $\begin{array}{c}30 \\
(44 \%)\end{array}$ & $\begin{array}{c}15 \\
(22 \%)\end{array}$ & $\begin{array}{c}56 \\
(82 \%)\end{array}$ & $\begin{array}{c}12 \\
(18 \%)\end{array}$ & $\begin{array}{c}5 \\
(7 \%)\end{array}$ & $\begin{array}{c}62 \\
(91 \%)\end{array}$ \\
\hline
\end{tabular}


Ellen A. A. Jaatun et al.: Radio-wave Therapy of Inferior Turbinates for Treatment of Intractable Vasomotor Rhinitis - A Clinical Study of the Subjective Long-term Outcome

Table 4. The pre- and postoperative occurrence of other symptoms associated with vasomotor rhinitis.

\begin{tabular}{|c|c|c|c|c|c|c|c|}
\hline \multicolumn{4}{|c|}{ Pre-operative } & \multicolumn{4}{c|}{ Post-operative } \\
\hline Secr. & Sneezing & Epistaxis & Headache & Secr. & Sneezing & Epistaxis & Headache \\
\hline 31 & 26 & 16 & 35 & 24 & 22 & 13 & 21 \\
\hline $20 \%$ & $17 \%$ & $10 \%$ & $23 \%$ & $16 \%$ & $15 \%$ & $9 \%$ & $14 \%$ \\
\hline
\end{tabular}

\section{Discussion}

This study indicates that radio-wave frequency therapy of the inferior turbinates for treatment of intractable vasomotor rhinitis is an easy method that is suitable for out-patient clinics and which gives subjective help from the main complaints in just above $80 \%$ of the cases without serious adverse effects.

The study is based solely on the subjective evaluation of the 151 patients without objective measurements such as rhinomanometry in different forms. The correlation between rhinomanometric values and the subjective scores in patients has been reported to be poor.[12]. Therefore, it is becoming more common than before to look at the subjective well-being of the patients as the most important criterion when evaluating the effect of a treatment on subjective complaints such as nasal blockage, nasal secretion and sneezing[3]. Since a reported subjective perception such as nasal congestion in this study led to a therapeutical approach (radio-wave frequency treatment), the reported degree of patients' satisfaction was regarded to be a sufficiently qualified measure of success.

Due to the fact that not all patients replied to all questions in the questionnaire it is not possible to draw any further conclusions from the observed difference between men and women regarding the results. A slight improvement in the occurrence of headache post-operatively as compared to pre-operatively in the whole material might be explained by the fact that 29 patients were also operated with UPPP that can reduce headache.

The nose is our main instrument to heat, clean and humidify the inhaled air. When performing surgery in the nose with the aim to offer relief from nasal congestion, one has to keep in mind which way the air stream will go afterwards. A total turbinectomy will normally leave a significant void in the lower part of the nose (i.e., where the inferior turbinate used to be). There will probably be less turbulence of the inhaled air after this type of procedure, and this will probably in turn both influence the sense of smell and cause polluted air to be deposited further down in the upper airway. By doing a radio-frequency treatment of the inferior turbinates the anatomy will not change a lot, and thus, it should also be possible to restore the filtration function of the nose and preserve a good sense of smell.

With previous methods of turbinectomy $[4,5]$ there have been troublesome epistaxis and the epithelium has been damaged. According to Elwany[8], the epithelium was intact one year after radio-wave frequency therapy, with an intense fibrosis in the submucosa. This might also be the reason why very little change in symptoms such as runny nose and sneezing was observed in our study after radio-wave frequency treatment. Elwany, in 1990[4] compared 4 different turbinectomy techniques, all of which showed poor long-term results. This is hardly surprising, since a turbinectomy is not primarily a causal treatment, but rather performed to achieve symptom relief. Thus, irrespective of method of turbinectomy it can be expected that the symptoms will return. When performing a radical turbinectomy there can seldom be any re-operation performed. With radio-wave frequency therapy, however, only the pseudoerectile tissue has been damaged, and in the case of recurrent symptoms there should be no problems in repeating the procedure.

An additional argument in favour of radio-wave frequency therapy is the low costs involved. The procedure is easy to learn and is quickly performed. The patients' comfort during surgery is good and the post-operative complaints are few and non-serious. Last, but not least, the treatment is suitable to be performed as an outpatient procedure.

\section{Conclusions}

This study supports the view that radio-wave frequency therapy is a low cost procedure that is easy to perform and has an acceptably good long-term effect on nasal congestion and other nasal complaints caused by turbinate hypertrophy in patients with vasomotor rhinitis unresponsive to local nasal steroid treatment.

\section{ACKNOWLEDGEMENTS}

At the time of the study Dr Ellen Jaatun was a resident at the Department of Otorhinolaryngology, Nordland hospital, Bodø, Norway. We thank the staff at the Department of Otorhinolaryngology, Nordland Central hospital, Bodø, Norway for their valuable help throughout the study. We also thank Mr. M.G Jaatun for computer support.

\section{REFERENCES}

[1] Becker B, Borum S, Nielsen K, Mygind N, Borum P. A time-dose study of the effect of topical ipratropium bromide on methacholine-induced rhinorrhea in patients with perennial non-allergic rhinitis. Clin Otolaryngol 1997; 22:132-4

[2] Fradis M, Malatskey S, Magamsa I, Golz A. Effect of submucosal diathermy in chronic nasal obstruction due to turbi- 
nate enlargement. Am J Otolaryngol 2002; 23:332-6.

[3] Lagerholm S, Harsten G, Emgård P, Olsson B. Laser-turbinectomy: long-term result. J Laryngol Otol 1999; 113:529-31.

[4] Elwany S, Harrison R. Inferior turbinectomy: Comparison of four techniques.

J Laryngol Otol 1990; 104:206-9.

[5] Ophir D, Schindel D, Halperin D, Marshak G. Long-term follow-up of the effectiveness and safety of inferior turbinectomy. Plast Reconstruct Surg 1992; 90:980-4.

[6] Ferri E, Armato E, Cavaleri S, Capuzzo P, Ianniello F. Argon plasma surgery for treatment of inferior turbinate hypertrophy: a long term follow up in 157 Patients.

ORL 2003; 65:206-10.

[7] Chevretton EB, Hopkins C, Black P, Tierney P, Smeeton NC. Degloving of the inferior turbinates: pilot study to assess the effectiveness of a new technique in turbinate reduction. $\mathrm{J}$ Laryngol Otol 2003; 117:866-70.
[8] Elwany S, Gaimaee R, Fattah HA. Radiofrequency bipolar submucosal diathermy of the inferior turbinates. Am J Rhinol 1999; 13:145-9.

[9] Li KK, Powell NB, Riley RW, Troell RJ, Guilleminault C. Radiofrequency volumetric tissue reduction for treatment of turbinate hypertrophy: A pilot study. Otolaryngol Head Neck Surg 1998; 119:569-73.

[10] Fischer Y, Gosepath J, Amedee RG, Mann WJ. Radiofrequency Volumetric Tissue Reduction (RFVTR) of Inferior Turbinates: A New Method in the treatment of Chronic Nasal Obstruction. Am J Rhinol 2000; 21:355-60.

[11] Classification of surgical procedures. (Nordic Medi co-Statist ical Committee) NOMESCO, Notex - Tryk\&Design a-s, Copenhagen 1996.

[12] Mygind N. Measurement of nasal airway resistance - is it only for article writers?

Clin Otolaryngol 1980; 5:161-3. 